\title{
Velocity Comparisons from Upward and Downward Acoustic Doppler Current Profilers on the West Florida Shelf
}

\author{
Dennis A. Mayer, Jyotika I. Virmani, and Robert H. Weisberg \\ College of Marine Science, University of South Florida, St. Petersburg, Florida
}

(Manuscript received 14 August 2006, in final form 21 February 2007)

\begin{abstract}
Current observations are compared from upward- and downward-looking acoustic Doppler current profilers (ADCPs) deployed on the West Florida Shelf (WFS). Despite regional differences, statistical analyses show good agreement between all sets of observations throughout the water column except in the upper few meters where all downward-looking ADCPs exhibit small, but significant, reduction in rms speed values. Evidence suggests that this reduction is mooring related. It is possible that the presence of near-surface bubbles caused by wave activity could bias the near-surface observations. Otherwise, either the upward- or downward-looking mooring systems produce equivalent observations with differences due to spatial variations.
\end{abstract}

\section{Introduction}

Shallow coastal ocean environments allow for a variety of ways of deploying current meters including bottom-mounted, upward-looking and surface buoymounted, downward-looking acoustic Doppler current profilers (ADCPs). In the case of a surface buoy, an ADCP may be mounted within a cage suspended below the buoy (Irish et al. 1992; Seim and Edwards 2007), within the buoy bridle (Weisberg et al. 1996), or within a well in the buoy hull (Winant et al. 1994). The possibility of contamination by buoy-induced motions has raised concerns over the accuracy of currents observed from a downward-looking, surface buoy-mounted ADCP. Complementing the investigations by Winant et al. (1994) and Seim and Edwards (2007), this study compares ADCP observations from bottom-mounted and surface buoy bridle-mounted configurations using data from five moorings on the West Florida Shelf (WFS; Fig. 1).

The mooring locations, the relative ADCP orientations, and the observing periods for each data record used in this study are given in Table 1 . The longest record used spans almost two years from 1 November

Corresponding author address: Dennis A. Mayer, College of Marine Science, University of South Florida, 140 Seventh Ave. S., St. Petersburg, FL 33701.

E-mail: dmayer@marine.usf.edu
1999 to 25 August 2001. These moorings were deployed on two orthogonal along-shelf and across-shelf lines (Fig. 1), intersecting at C10. The largest separation between the across-shelf moorings, $\mathrm{C} 06$ and C11, was 20.4 $\mathrm{km}$. Closest to shore, $\mathrm{C} 11$ was on the $20-\mathrm{m}$ isobath, and farthest from shore, C06 was on the 30-m isobath. The along-shelf line of $\mathrm{C} 01, \mathrm{C} 10$, and $\mathrm{C} 02$ was on the $25-\mathrm{m}$ isobath such that $\mathrm{C} 01$ is northernmost at $4.4 \mathrm{~km}$ northnorthwestward of $\mathrm{C} 10$ and $9.2 \mathrm{~km}$ north-northwestward of $\mathrm{C} 02$.

With these five moorings carrying ADCPs in upward and downward configurations, we can determine regional velocity differences observed by moorings of the same type and compare observations obtained from moorings of different types. Upward-looking RD Instruments (RDI) 300-kHz broadband (BB) ADCPs with a $20^{\circ}$ transducer head design were mounted in trawl-resistant bottom mounts deployed on the seafloor at $\mathrm{C} 11, \mathrm{C} 01$, and for part of the $\mathrm{C} 02$ deployment (Table $1)$. The transducer heads were positioned approximately $1 \mathrm{~m}$ above the seafloor; hence, the first data bin was approximately $2 \mathrm{~m}$ above the bottom. Downwardlooking RDI ADCPs were deployed at C06, C10, and at $\mathrm{C} 02$ during the time that the $\mathrm{C} 02$ site had a surface mooring. At $\mathrm{C} 10$ and $\mathrm{C} 02$ a $600-\mathrm{kHz}$ narrowband (NB) ADCP with a $30^{\circ}$ transducer head design was mounted in the buoy bridle. At C06 a 300-kHz BB was mounted in the surface buoy bridle. In these cases the transducer heads were positioned approximately $1.5 \mathrm{~m}$ below the

DOI: 10.1175/JTECH2094.1 


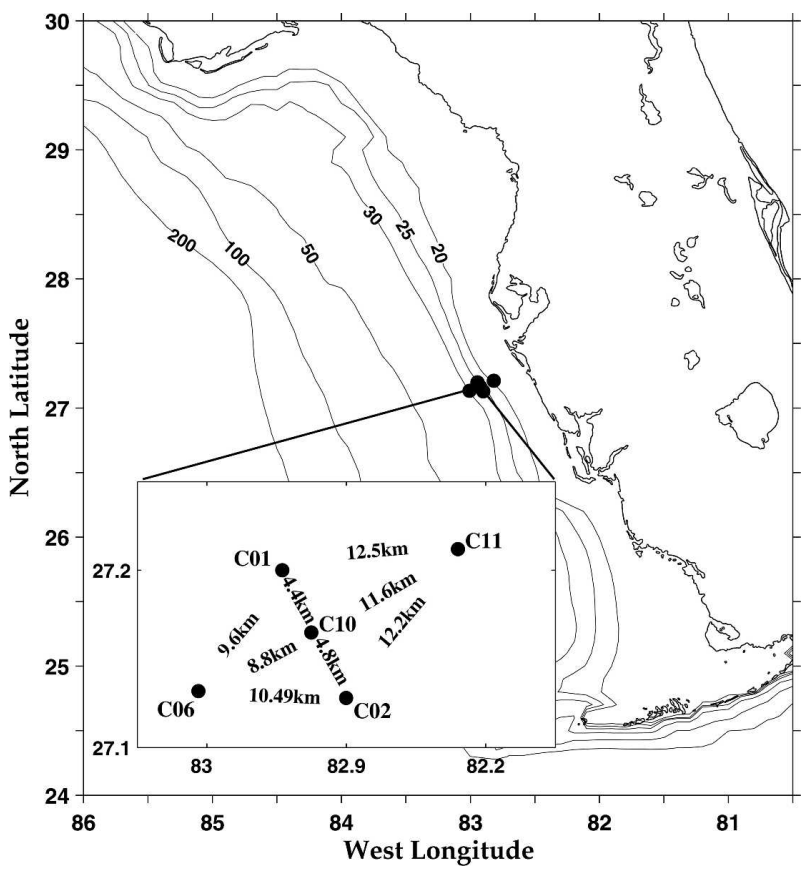

FIG. 1. Location of moorings on the West Florida Shelf. Bathymetric contours are in meters. Distances between moorings are also given. ADCP orientations are upward (C01, C02/partial, C11) and downward (C02/partial, C06, C10).

surface; hence, the first data bin was at a depth of approximately $4 \mathrm{~m}$. All of the ADCPs sampled each second over the first 6 min of each hour to produce hourly averaged values. All compass observations were corrected for deviation. Bin sizes varied, depending on the mooring, from 0.5 to $2 \mathrm{~m}$, so the data were interpolated onto $1-\mathrm{m}$ integer depths for uniformity. The nearsurface (for upward looking) and near-bottom (for downward looking) bins, found to be contaminated by surface and bottom sidelobe reflections, respectively,

TABLE 1. Mooring locations, time periods of ADCP, and ADCP configurations.

\begin{tabular}{ccclc}
\hline \hline Mooring & Lat & Lon & $\begin{array}{c}\text { ADCP } \\
\text { orientation }\end{array}$ & Time periods \\
\hline C01 & $27^{\circ} 12.0^{\prime} \mathrm{N}$ & $82^{\circ} 56.75^{\prime} \mathrm{W}$ & Upward & $\begin{array}{c}1 \text { Nov 1999-25 } \\
\text { Aug 2001 }\end{array}$ \\
C02 & $27^{\circ} 7.7^{\prime} \mathrm{N}$ & $82^{\circ} 54.0^{\prime} \mathrm{W}$ & Upward & $\begin{array}{c}1 \text { Nov 1999-22 } \\
\text { Jun 2000 }\end{array}$ \\
C02 & $27^{\circ} 7.7^{\prime} \mathrm{N}$ & $82^{\circ} 54.0^{\prime} \mathrm{W}$ & Downward & $\begin{array}{c}\text { Jul 2000-8 } \\
\text { Mar 2001 }\end{array}$ \\
C06 & $27^{\circ} 7.9^{\prime} \mathrm{N}$ & $83^{\circ} 0.35^{\prime} \mathrm{W}$ & Downward & $\begin{array}{c}1 \text { Nov 1999-25 } \\
\text { Aug 2001 }\end{array}$ \\
C10 & $27^{\circ} 9.9^{\prime} \mathrm{N}$ & $82^{\circ} 55.5^{\prime} \mathrm{W}$ & Downward & $\begin{array}{c}\text { Nov 1999-25 } \\
\text { Aug 2001 }\end{array}$ \\
C11 & $27^{\circ} 12.7^{\prime} \mathrm{N}$ & $82^{\circ} 49.2^{\prime} \mathrm{W}$ & Upward & $\begin{array}{c}1 \text { Nov 1999-25 } \\
\text { Aug 2001 }\end{array}$ \\
\hline
\end{tabular}

were removed before interpolating. To obtain the along- and across-shelf velocity components, the observed east and north components were rotated $28^{\circ}$ clockwise (which is the same as rotating the coordinate system $28^{\circ}$ anticlockwise). In the ensuing discussions the terms upward and downward refer to instrument orientations on the moorings.

\section{Observations}

Ten-day low-pass-filtered along- and across-shelf velocity component contours at all five mooring locations are shown in Fig. 2 subsampled from October to December 2000, an interval typical of the fall/winter season on the WFS. During this time the $\mathrm{C} 02$ record was measured with a downward-looking ADCP (Table 1). Regardless of instrument orientation, the along-shelf velocity components are in good agreement. In early November, moorings along the same isobath observe greater across-shelf (onshore) velocities at C01 (upward) than at $\mathrm{C} 10$ or $\mathrm{C} 02$ (both downward), whereas moorings on different isobaths C01 (upward) and C06 (downward) show similarly strong onshore currents with the across-shelf velocity at C06 (downward) being greater than at $\mathrm{C} 10$ or $\mathrm{C} 02$. For comparison, in midDecember an offshore component, common between all moorings, is strongest at $\mathrm{C} 01$ (upward) and $\mathrm{C} 10$ (downward) relative to the other moorings. These variations between moorings, given the minor differences in the along-shelf velocity components, suggest real regional differences in the circulation without regard to the instrument's upward or downward orientations.

These regional differences may be quantified using hourly, vertically averaged along-shelf velocity components for the first part of the record from 1 November 1999 to 22 June 2000 (Fig. 3). The upper two panels show data from similar upward moorings ( $\mathrm{C} 01$ and $\mathrm{C} 02$ ) positioned along the shelf on the same isobath and downward moorings (C10 and C06) positioned across the shelf on different isobaths. For $\mathrm{C} 10$ and $\mathrm{C} 06$ the data are averaged between 4 and $22 \mathrm{~m}$. The lower two panels show data for upward and downward moorings positioned along the shelf ( $\mathrm{C} 01$ and $\mathrm{C} 10)$ and across the shelf (C11 and C10), respectively. For C11 and C10 the data are averaged between 4 and $18 \mathrm{~m}$. Visually there are no immediately discernable differences between the data observed with upward- or downward-oriented ADCPs. Differences in mean values are larger between the across-shelf moorings than between the along-shelf moorings; the largest currents are farthest offshore and the smallest currents are closest to shore. Individual mooring data variances and the variances of the differ- 

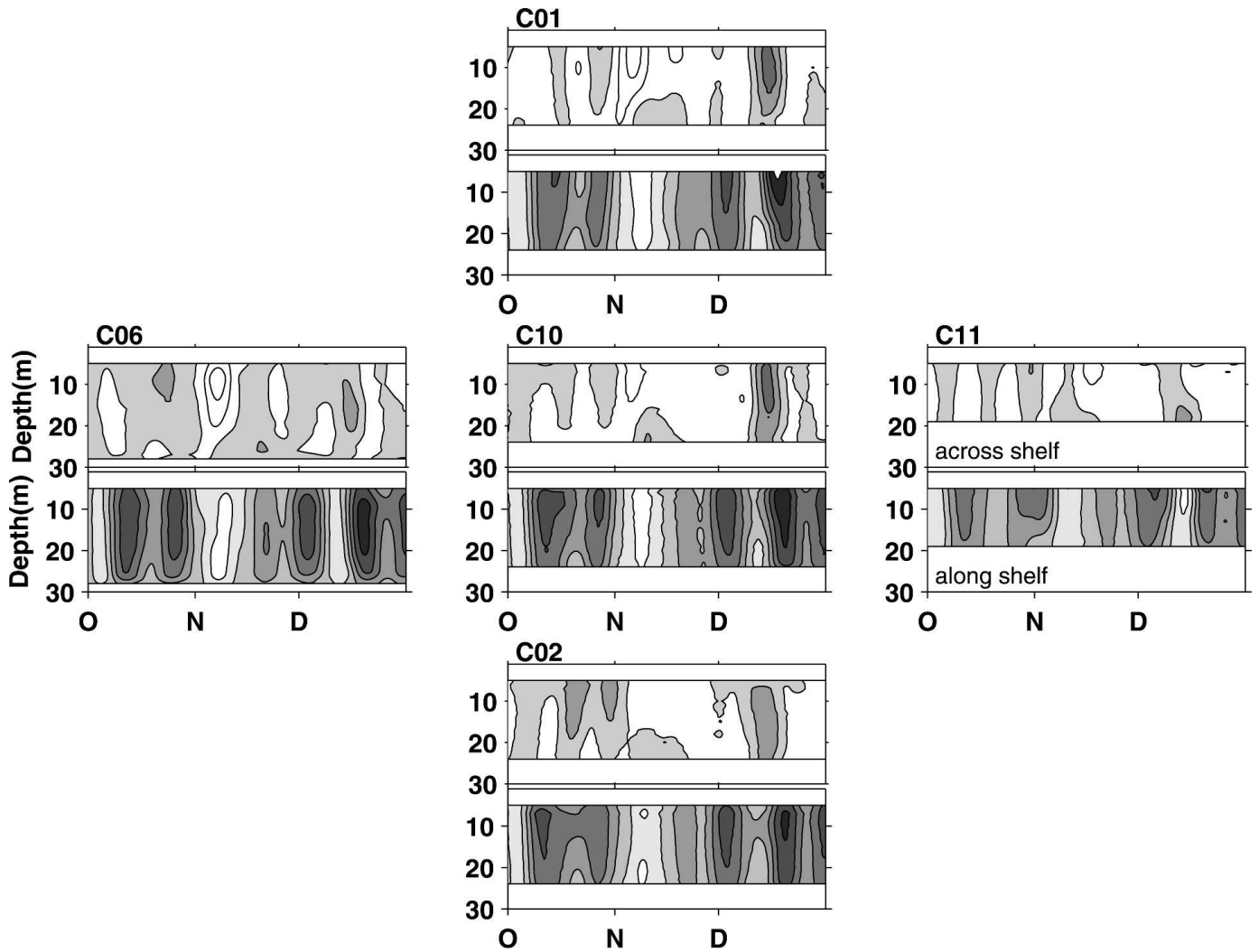

FIG. 2. Ten-day low-pass-filtered velocity contours for all five moorings on the West Florida Shelf from OctoberDecember 2000. ADCP orientations are upward (C01, C02/partial, C11) and downward (C02/partial, C06, C10). The north and east velocity components have been rotated $28^{\circ}$ clockwise from north to provide along-shelf and across-shelf components, respectively. Shaded regions are negative values. The zero contour separates shaded and unshaded areas. Contour intervals are 5 and $2 \mathrm{~cm} \mathrm{~s}^{-1}$ for along-shelf and across-shelf components, respectively.

ence between each mooring pair were also computed (not shown). Comparing similar instrument orientations along the shelf $(\mathrm{C} 01, \mathrm{C} 02)$, the variance of the differences are $11 \%-12 \%$ ( $30 \% \mathrm{rms})$ of the individual variances. This increases to $17 \%-21 \%(45 \% \mathrm{rms})$ across the shelf (C10, C06); however, the across-shelf moorings are closer together than the along-shelf moorings (Fig. 1) suggesting greater variability across rather than along the shelf. Comparing upward and downward instruments $(\mathrm{C} 01, \mathrm{C} 10)$, which are $4.4 \mathrm{~km}$ apart, the variance of the differences is only $6 \%-8 \%(25 \% \mathrm{rms})$. This smaller value is probably a consequence of the moorings being closer together, supporting the assumption of regional differences in the velocity field regardless of instrument orientation. The inference here is that regional differences are essentially independent of mooring orientation.

Five-day subsets of hourly along-shelf velocity data, beginning 1 November 1999, at three depths (near surface, middle of water column, near bottom) provide a more detailed look at these observations for the case of a typical fall/winter extratropical frontal system passage (Fig. 4). The WFS is characteristically affected by extratropical fronts from October through June (e.g., Virmani and Weisberg 2003). Although all possible combinations between moorings were examined for many other time periods, the observations shown in Fig. 4 are representative of the temporal variability between mooring pairs as previously outlined for Fig. 3. The observations between moorings during an event are generally in good agreement. Comparing upward and downward observations, $\mathrm{C} 01, \mathrm{C} 10$ and $\mathrm{C} 11, \mathrm{C} 10$ also provide good agreement and hence the observations, whether obtained from upward- or downward-looking instruments, are qualitatively indistinguishable.

\section{Analysis and results}

\section{a. Root-mean-square}

Total rms (along-shelf plus across-shelf) distributions with depth for these mooring pairs, calculated from 1 November 1999 to 22 June 2000, are shown in Fig. 5. 


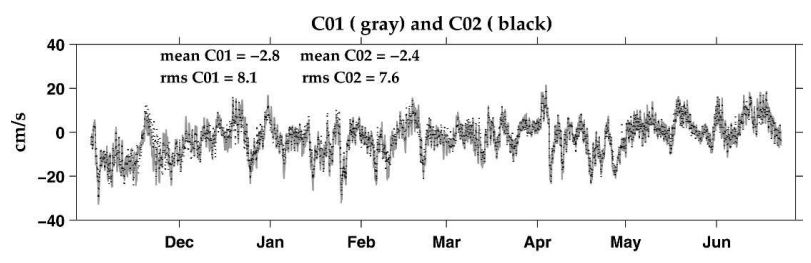

C10 ( gray) and C06 ( black)

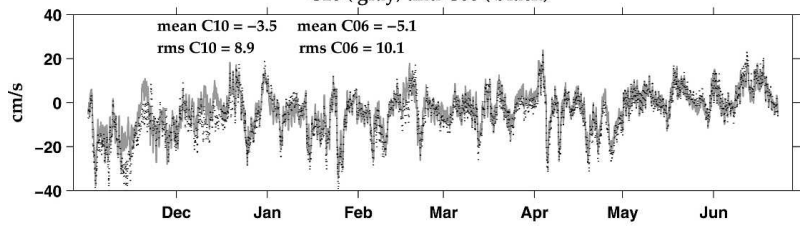

C01 ( gray) and C10 ( black)
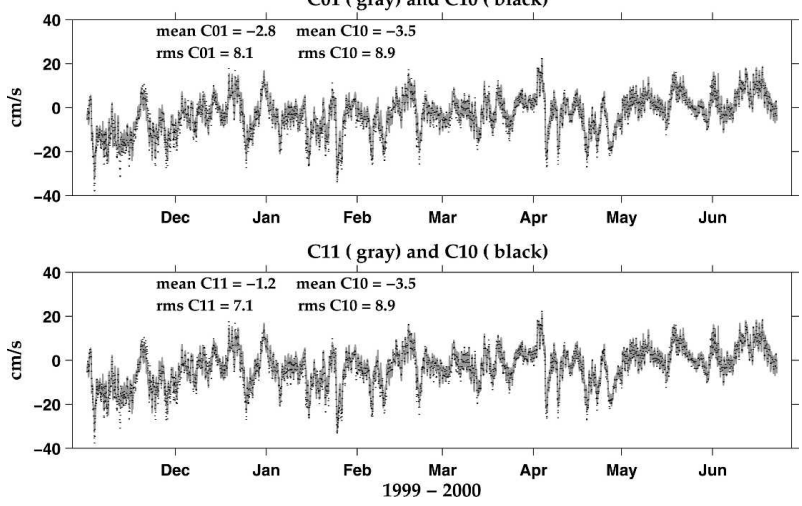

FIG. 3. Depth-averaged along-shelf velocity components showing comparisons between along-isobath and across-isobath mooring locations spanning the time period from 1 Nov 1999 to 22 Jun 2000. ADCP orientations are upward (C01, C02, C11) and downward (C06, C10). Data are unfiltered hourly samples. Depth averages were computed from 4 to $22 \mathrm{~m}$ for all moorings except $\mathrm{C} 11$, which was computed from 4 to $18 \mathrm{~m}$ because of its shallower location.

Rms values indicate the differences in variability between mooring pairs. The differences in rms throughout the water column for moorings positioned along the shelf are smaller than for moorings positioned across the shelf. This is consistent with the qualitative results of across-shelf variability being larger than along-shelf variability. The rms near the surface at $\mathrm{C} 02$ is less than at $\mathrm{C} 01$ by $5 \%$ but gradually approaches $\mathrm{C} 01$ values with depth. The rms profiles near the surface at C10 are $9 \%$ smaller than at $\mathrm{C} 06$, but this difference increases with depth so that the deepest rms at $\mathrm{C} 10$ is $23 \%$ smaller. The rms at C11 is considerably smaller than that at C10, which is consistent with observations at a shallower water depth.

In addition to the expected regional differences, however, there is a persistent and significant reduction of rms values in the upper 5-7 m of the water column in all of the downward-looking instruments, as seen in the profile at $\mathrm{C} 10$. The means exhibit a similar reduction (not shown). This feature is absent from the rms pro- files of upward-looking instruments. At $\mathrm{C} 06$ the rms value at the surface also decreases; however, the deployment used to calculate the values shown in Fig. 5 differs from other deployments at the C06 site and therefore the reduction is not as obvious. This deployment was the only one with half-meter bin sizes. Additionally, it was contaminated by a large number of inline instruments, resulting in a removal of almost $50 \%$ of the data. This in-line instrument contamination contributed to changes in the rms, producing more variability in the profile, that were still within the manufacturer's rms error for the instrument. The other profiles in Fig. 5 are consistent with all upward and downward moorings. The discernable difference between upward versus downward moorings (e.g., C01 and $\mathrm{C} 10$ ) in the upper water column is an approximate $8.5 \%$ reduction in $\mathrm{rms}$, which translates to approximately $9 \%$ reduction in the observed velocity. Therefore, for typical observed velocities of $5-10 \mathrm{~cm} \mathrm{~s}^{-1}$ on the WFS, the near-surface observations made by a downward-looking ADCP are $0.5-0.9 \mathrm{~cm} \mathrm{~s}^{-1}$ smaller than for an upward-looking ADCP. As will emerge in the discussion, we believe that this reduction of the near-surface rms is a consequence of the mooring configuration.

\section{b. Vector correlation}

The vector correlation provides a correlation amplitude, a regression coefficient (or gain), and the veering angle between a pair of two-dimensional vector time series (Kundu 1976). The visual coherence of velocities in Fig. 3 can be quantified by examining the vector correlation amplitudes for the depth-averaged velocity between moorings (Fig. 6a). Hourly data spanning 1 November 1999-22 June 2000 are used, and results show that all correlations are greater than 0.8 .

The vector correlation with depth is also examined (Fig. 6b). The preferred direction of velocity on the WFS is along shelf. This direction is obtained from the orientation of the principal axes. In Fig. 6b, the solid lines in the left panels show the orientation of the principal axes of the data. They are all negative and become increasingly negative (anticlockwise) with depth, which is consistent with a geostrophic interior and a bottom Ekman layer. These figures also show that the orientations of the principal axes between moorings are within $5^{\circ}$ of each other at all depths, except near the bottom for $\mathrm{C} 10$ and $\mathrm{C} 06$, which are within $10^{\circ}$ of each other. This means that along-shelf motion at all mooring locations is very similar. The dashed lines show the covariability, in terms of the veering angle, between velocity vectors for the mooring pairs. The veering angle is the average veering of one vector time series with 


\section{C01 (gray) C02 (black)}
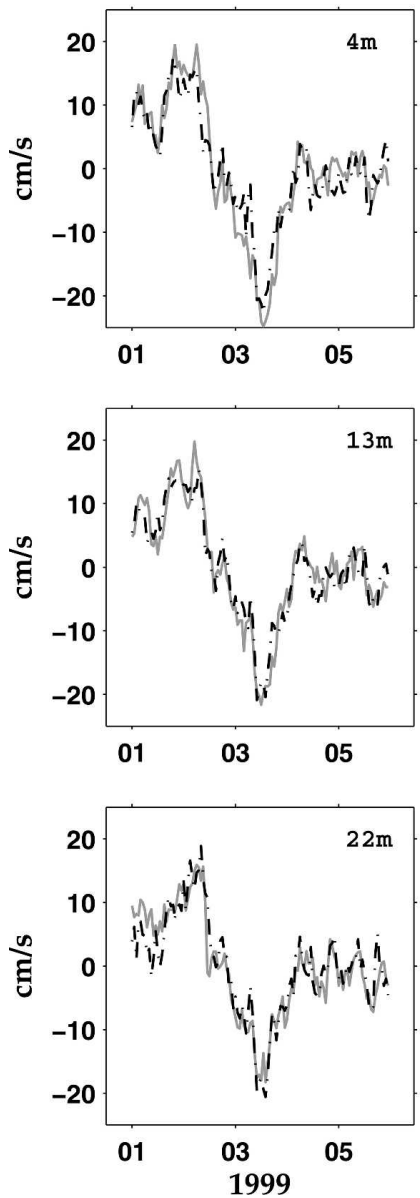
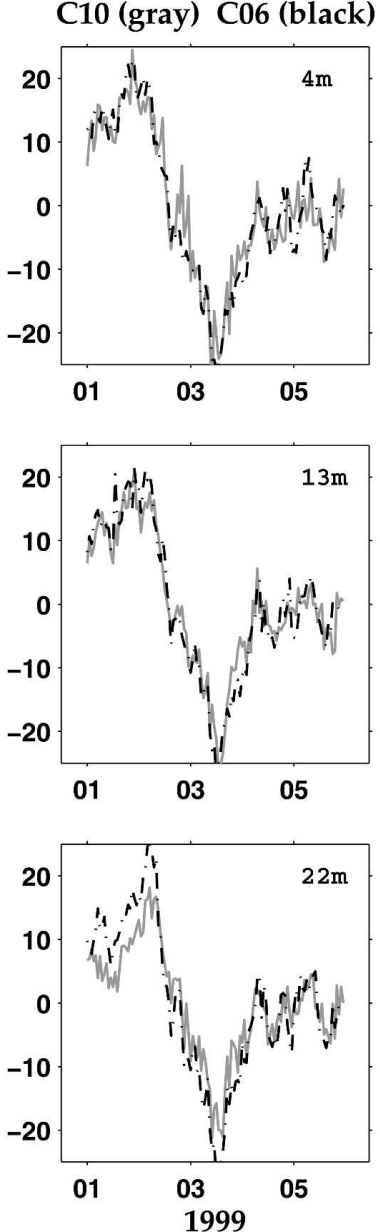

C01 (gray) C10 (black)
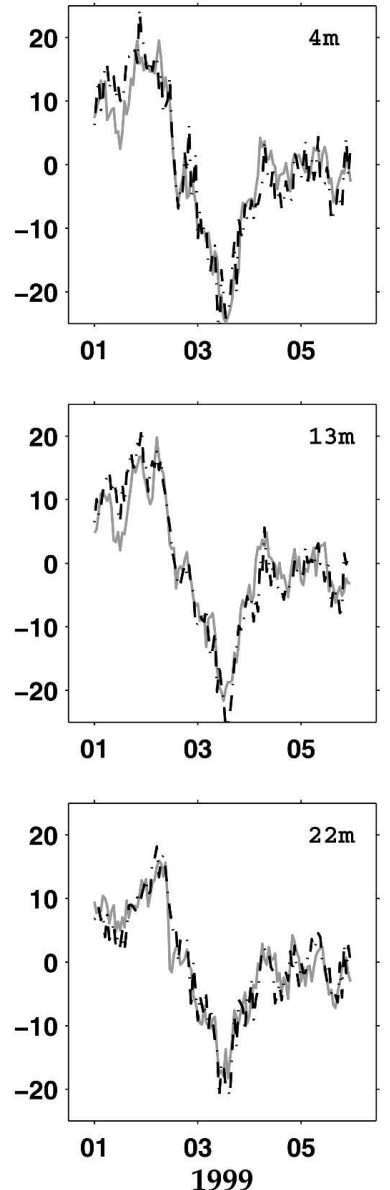

C11 (gray) C10 (black)
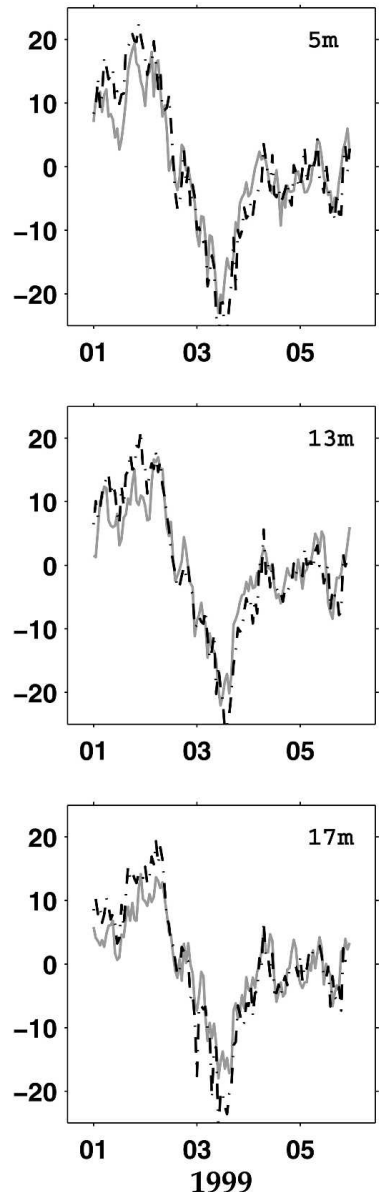

FIG. 4. Along-shelf velocity components during a 5-day period in November 1999 showing the shelf response to a typical late fall/winter extratropical synoptic frontal system. ADCP orientations are upward (C01, C02, C11) and downward (C06, C10). Mooring comparisons are as in Fig. 3 for 4-m (near surface), 13-m (middepth), and 22-m (near bottom) depths for all moorings except C11, which are 5,13 , and $17 \mathrm{~m}$.

respect to the other. On the WFS these are within $5^{\circ}$ between moorings, except for comparisons with $\mathrm{C} 11$ (not shown). C11 is on a shallower isobath where frictional effects play a more important role; therefore, C11 will not be discussed further. This difference improves substantially when comparing 40-h low-passfiltered data (not shown) that are not influenced by tidal motions. The improvement is approximately half that of the unfiltered data (includes tides). This further supports the notion that differences between observations at different moorings are due to real regional variability rather than to instrument orientation. Additionally, at 4-, 13-, and 22-m depths, the unfiltered hourly directions were differenced. The average speeds between the mooring pairs were then binned against the differenced directions. An environment free of random variations with no regional differences or instrument errors would result in a single bin, centered at $0^{\circ}$, that includes all the observed speeds. Regional differences produce a frequency distribution (not shown) that resembles a normal distribution and is symmetric about $0^{\circ} \pm 2^{\circ}$. This is within the accuracy of the compass according to the manufacturer (RDI).

The vector correlation amplitudes (gray lines in the right panels) are all greater than 0.8 throughout the water column. The significance levels (SLs) of these correlations are determined by normalizing the correlation with the large lag standard error (LLE). Following Sciremammano (1979), the data from these moorings result in an LLE of 0.05-0.08 and more than 150 degrees of freedom. The SL obtained from this is above $99 \%$ for the null hypothesis with an independence time scale greater than $30 \mathrm{~h}$. This independence time scale indicates that a velocity observation at one moment is independent from another velocity observation $30 \mathrm{~h}$ removed, a physically reasonable finding because tidal 

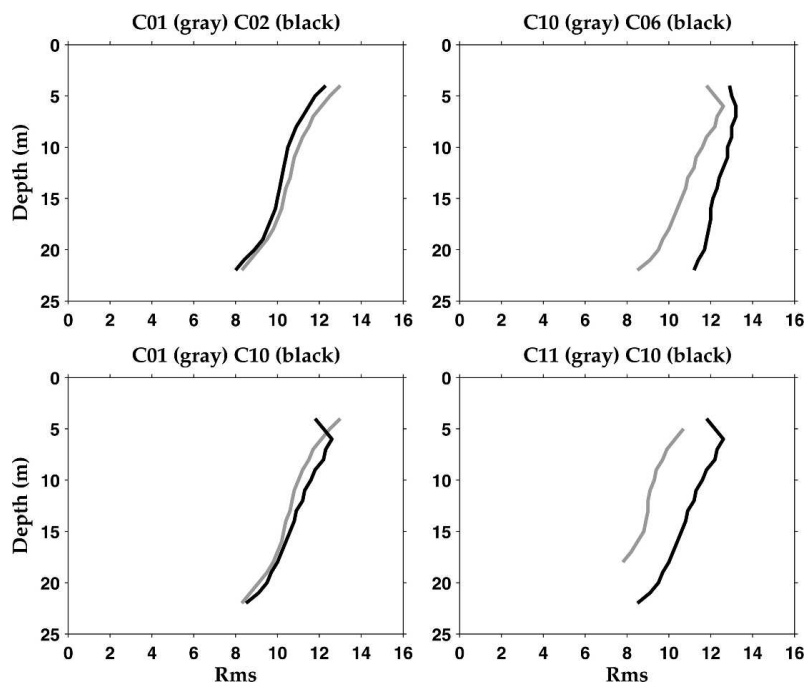

FIG. 5. Depth profiles of total (along shelf plus across shelf) rms $\left(\mathrm{cm} \mathrm{s}^{-1}\right)$. ADCP orientations are upward $(\mathrm{C} 01, \mathrm{C} 02, \mathrm{C} 11)$ and downward $(\mathrm{C} 06, \mathrm{C} 10)$. Mooring comparisons and time period used as in Fig. 3.

motions (periods less than $27 \mathrm{~h}$ ) are highly correlated. Assuming that the relationships between the moorings are linear, we can use the gain (black lines, right panels) and the observations from one mooring to provide a prediction of observations at the other mooring. The gain differs from the correlation between $\mathrm{C} 10$ and $\mathrm{C} 06$, and is larger and increasing with depth because of larger velocities at $\mathrm{C} 06$, which is in deeper water. Between $\mathrm{C} 01$ (upward) and C10 (downward) the gain decreases rapidly above $6 \mathrm{~m}$. This is consistent with the degradation of rms described above.

\section{c. Scalar spectral analysis}

Autospectra of the time series (Fig. 7) for the alongand across-shelf velocity components at $13 \mathrm{~m}$ (middepth) show good agreement between moorings. Spectra at other depths are also equivalent. Peaks at the semidiurnal and diurnal periods are in response to tidal influences. There are no appreciable differences in the along-shelf spectra at all frequencies, and the acrossshelf spectra are also virtually indistinguishable between the moorings at most frequencies. At the high frequencies, near the Nyquist $(0.5 \mathrm{cph})$, the instrument background level variance is approximately 1.5 $\left(\mathrm{cm} \mathrm{s}^{-1}\right)^{2}$ for all moorings, giving an rms value of 1.2 $\mathrm{cm} \mathrm{s}^{-1}$. This compares well with the manufacturer's rms errors for the instruments, which are 0.6 and $1 \mathrm{~cm} \mathrm{~s}^{-1}$ for the 600- and 300-kHz ADCPs, respectively, suggesting that our observations are all of high quality. Additionally, there is a subtle difference at the highest frequencies such that the along-shelf spectrum levels out

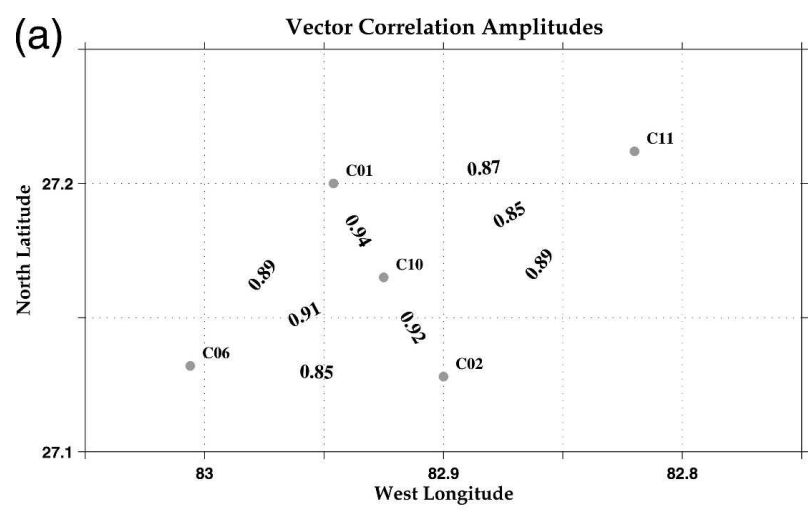

(b)
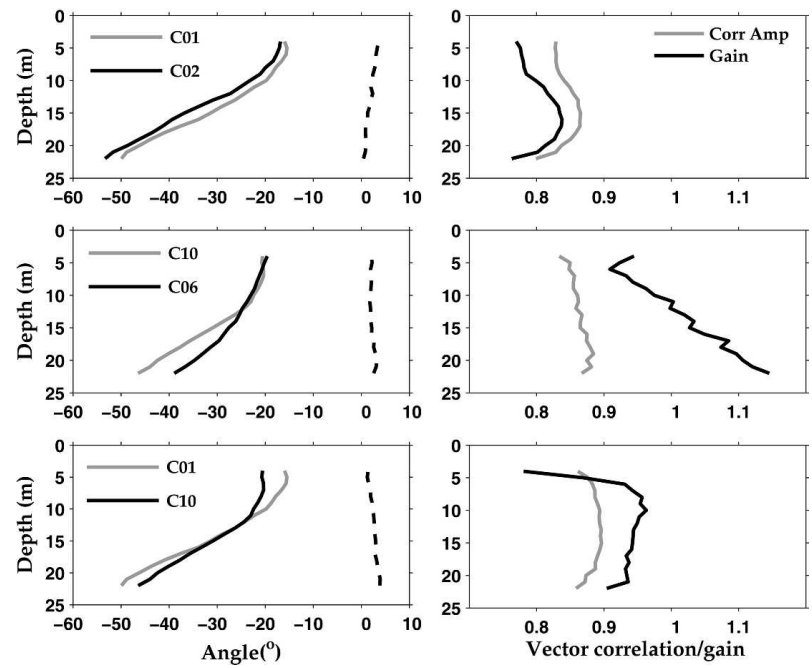

FIG. 6. ADCP orientations are upward $(\mathrm{C} 01, \mathrm{C} 02, \mathrm{C} 11)$ and downward (C06, C10). Mooring time period used is as in Fig. 3. (a) Depth-averaged vector correlation amplitudes between each pair of moorings. (b) (left) Depth profiles for along-isobath and across-isobath mooring pairs of major axis orientation angles (solid lines, $+\mathrm{CW}$ with respect to north) and veering angles (dashed lines, average angle between vectors, $+\mathrm{CW}$ with respect to each mooring denoted by the gray solid lines). (right) Vector correlations between moorings. Amplitude (gray) and gain/ regression coefficient (black).

compared with the across-shelf spectrum, which continues to decline. This implies an anisotropic relationship between these components at turbulent length scales and is seen in all mooring comparisons. Therefore, these scales can be detected regardless of instrument orientation.

Cross-spectral analysis (not shown) shows that wherever there is significant energy the phases are close to zero and the coherence is significantly above the $90 \%$ SL, with highest values in the along-shelf components. Where the phases are not zero, both the coherence and energy densities are small. Summarily, the along-shelf coherence squared is close to 1.0 at synoptic and lower 

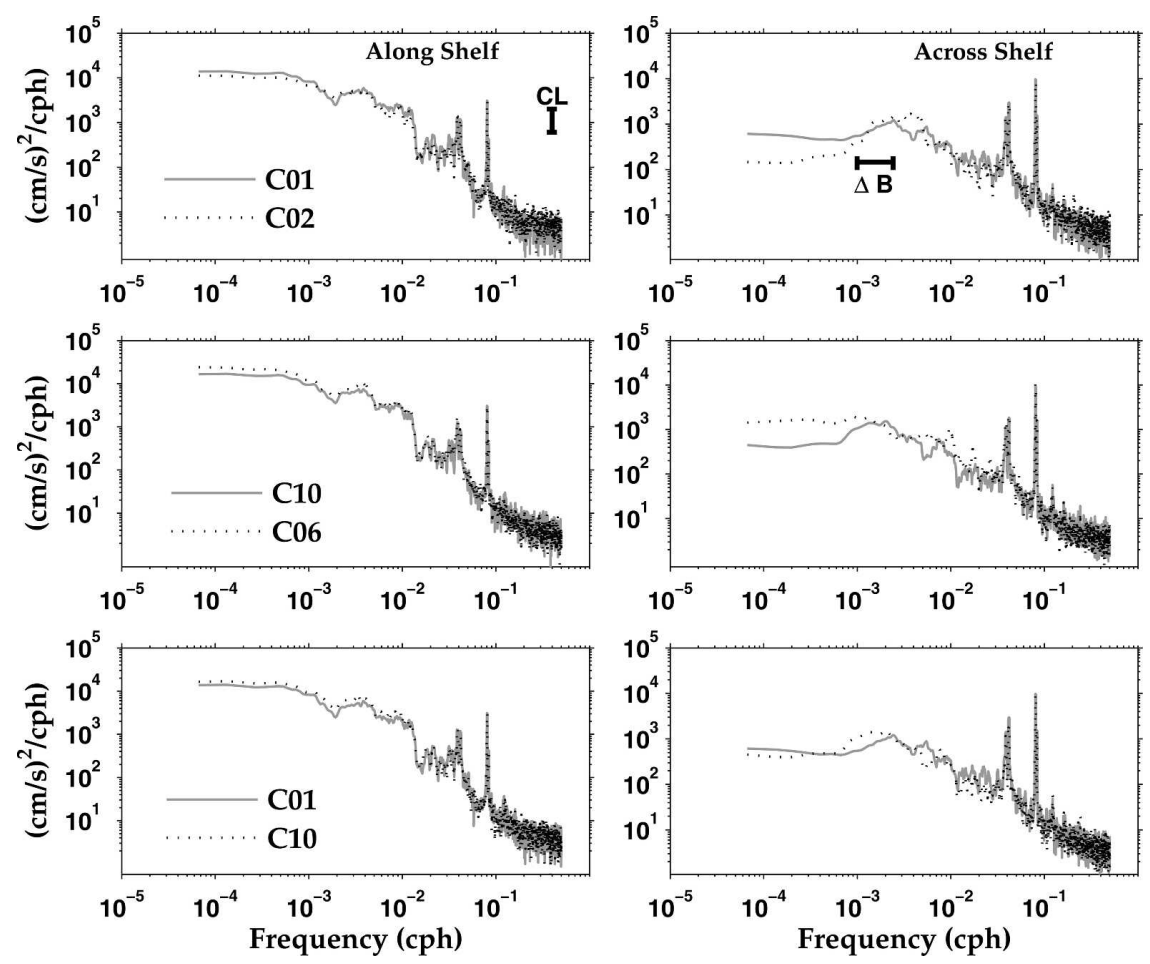

FIG. 7. Autospectra for the (left) along-shelf and (right) across-shelf velocity components for mooring pairs as in Fig. 6 at 13-m depth. ADCP orientations are upward (C01, C02) and downward (C06, C10). CL denotes the $95 \%$ confidence limits for spectral density estimates, which were averaged over the bandwidth $(\Delta B) 0.0014 \mathrm{cph}$.

frequencies and at tidal frequencies, and decreases below 0.8 for periodicities below three days. In the acrossshelf direction the coherence squared is not as high and only reaches close to 1.0 at tidal frequencies. There are no phase differences between the moorings except for the across-shelf components in the lowest frequencies (periods greater than a month) where the seaward moorings lead shoreward moorings. In all cases spectral comparisons across the shelf are not as good as along the shelf regardless of instrument type, suggesting regional differences in the velocity field. Interestingly, during the time when $\mathrm{C} 02$ carried a downward-looking instrument, the comparisons between $\mathrm{C} 01$ and $\mathrm{C} 02$ (not shown) are not as good as the comparisons between $\mathrm{C} 01$ and $\mathrm{C} 10$ (also upward and downward looking). This further suggests regional environmental differences versus differences in instrument orientation.

\section{d. Rotary spectral analysis}

There are basically two classes of motions on the WFS. The first is predominantly in the lower frequencies-for example, in the synoptic band-and is mostly aligned along the shelf. The second class of motions relates to the higher frequencies-for example, the tidal bands whose motions have a large across-shelf component. Rotary spectral analysis allows us to quantitatively examine the geometry of these two classes as a function of frequency. Rotary auto- and cross-spectral quantities at $\mathrm{C} 01$ and $\mathrm{C} 10$, computed using data for the full record length at 13-m depth, are shown in Figs. 8 and 9.

For the autospectra, the low-frequency results (periods greater than 2 days) are separated from the highfrequency results (periods less than 2 days) in Figs. $8 \mathrm{a}$ and $8 \mathrm{~b}$, respectively. Decomposing a velocity vector sequence using Fourier transforms results in an ellipse that pertains to the average geometry of the motion. The Fourier transform has negative and positive frequencies corresponding to clockwise $(\mathrm{CW})$ and anticlockwise (ACW) components of the ellipse, respectively. The autospectra describes the elliptical structure for each mooring via the $\mathrm{CW}$ and ACW spectral density, the stability $\left(\gamma^{2}\right)$, the axis ratio, the principal axis orientation $(\alpha)$, and the semimajor axis. As described earlier, the orientation of the principal axis gives the preferred direction of currents on the WFS. The stability is a measure of the geometric coherence of the ellipse, and the axis ratio and semimajor axis are geomet- 


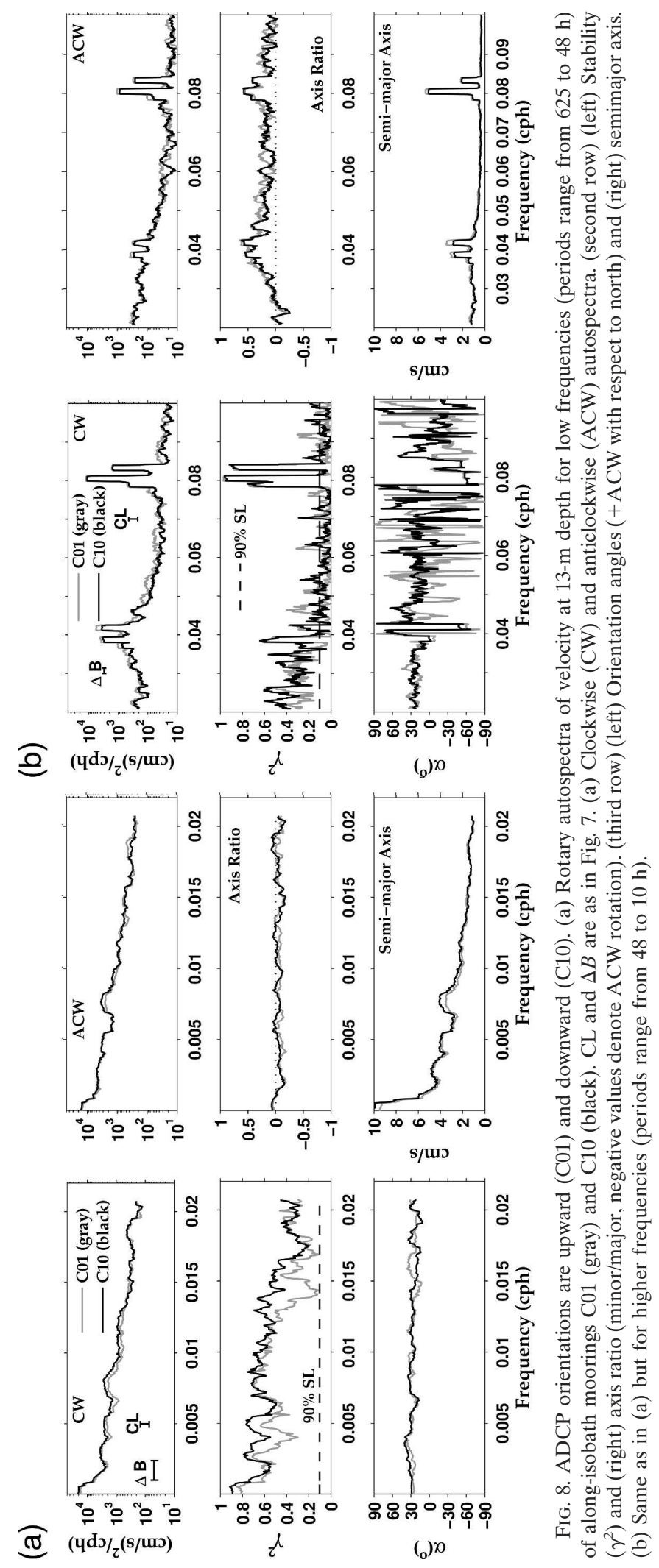



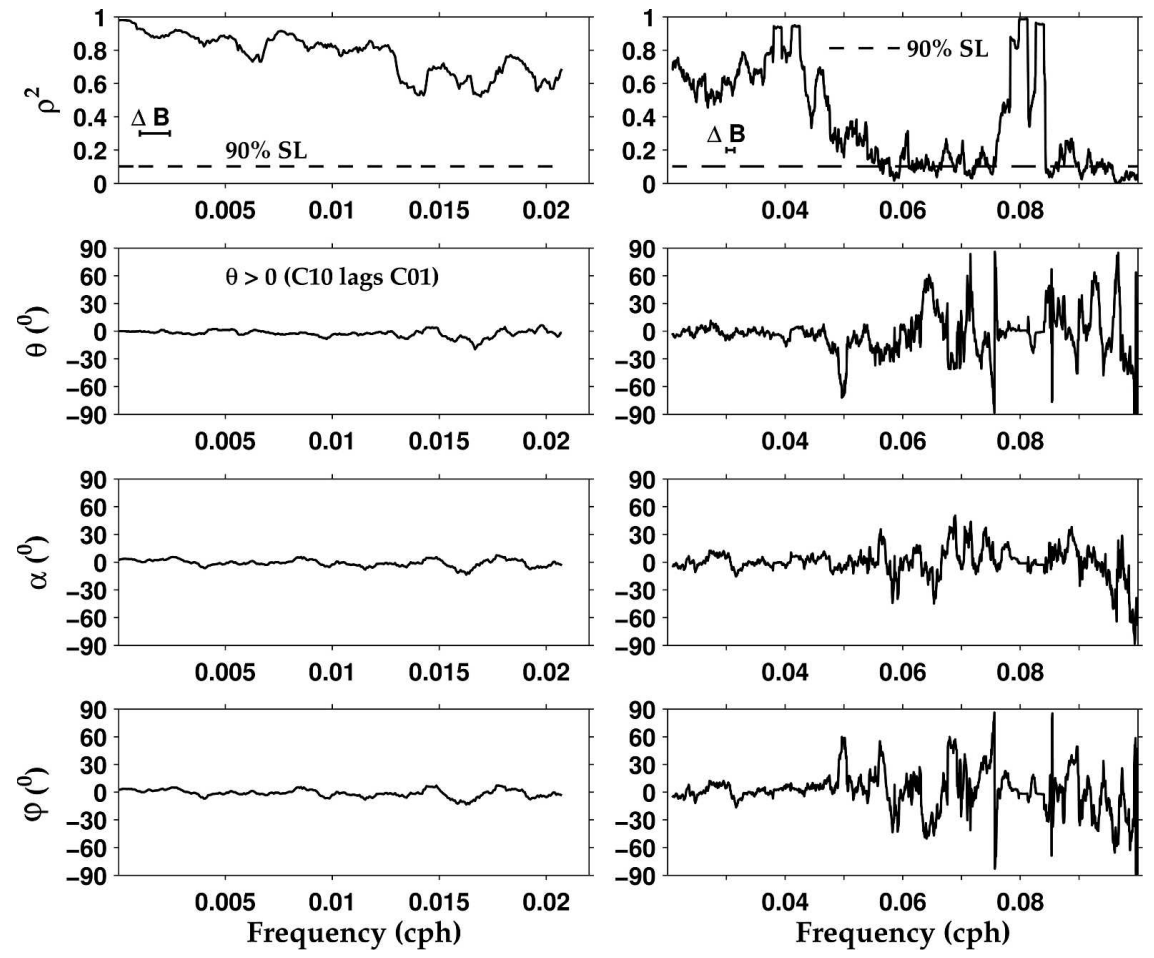

FIG. 9. ADCP orientations are upward (C01) and downward (C10). Rotary cross spectra of velocity at $13 \mathrm{~m}$ between $\mathrm{C} 01$ and $\mathrm{C} 10$. (left) Low frequencies and (right) higher frequencies have the same ranges as in Fig. 8. $\Delta B$ is as in Fig. 7. (top row) Vector correlation squared $\left(\rho^{2}\right)$. (second row) Vector phase lag $(\theta)$. (third row) Veering angle $(\alpha)$ is the vector orientation of $\mathrm{C} 10+\mathrm{ACW}$ with respect to the vector orientation of C01. (fourth row) Relative ellipse orientation $(\varphi)$ is the principal axes of $\mathrm{C} 10+\mathrm{ACW}$ with respect to the principal axes of $\mathrm{C} 01$.

ric properties of the ellipse. An axis ratio close to zero indicates rectilinear motion on the shelf. In contrast, values near unity indicate circular motion, with the sign indicating the direction of rotation.

The low-frequency autospectra (Fig. 8a) show that the CW and ACW energy are essentially the same. This is consistent with rectilinear motion along the shelf, as confirmed by orientation angles of approximately $30^{\circ}$ anticlockwise from north and a small axis ratio. The stability is above the $90 \%$ SL (dashed line) and the semimajor axes for both moorings range from 1 to $10 \mathrm{~cm} \mathrm{~s}^{-1}$.

At higher frequencies (Fig. 8b) the energy is concentrated around the two tidal bands (diurnal and semidiurnal) and the CW energy is dominant (the rotation of the ellipse is $\mathrm{CW}$ ). Also the axis ratios are larger and the stability is above the $90 \%$ SL. Outside the tidal frequencies the stability is low except for frequencies whose periods are greater than $30 \mathrm{~h}$ where the motions are nearly rectilinear along the shelf. The orientation angles for the two diurnal tidal peaks are clustered around $0.04 \mathrm{cph}$ and organized both along and across the shelf for $O_{1}\left(0^{\circ}\right)$, and across the shelf for $K_{1}\left(-50^{\circ}\right)$, with $O_{1}$ being the lower frequency. The three semidiurnal peaks, $N_{2}, M_{2}$, and $S_{2}$, are clustered around 0.08 cph and oriented across the shelf with angles between $-40^{\circ}$ and $-60^{\circ}$. The energy for $N_{2}$ is not separated from $M_{2}$ and is at a slightly lower frequency adjacent to $M_{2}$. The semimajor axes for both tidal bands range from 2 to nearly $6 \mathrm{~cm} \mathrm{~s}^{-1}$.

The above rotary autospectral analyses clearly show that the velocity fields observed from upward and downward instruments are similar across all frequencies.

Augmenting the results from Fig. 6, the rotary cross spectra describe the frequency dependence of the vector relationships of the velocity field between the two moorings, C01 and C10 (Fig. 9). These spectral analyses were conducted using 13-m velocity data from an upward and downward mooring, and the results are divided into low frequencies (left) and high frequencies (right). The quantities computed include the vector correlation squared $\left(\rho^{2}\right)$, the vector phase lag $(\theta)$, the veering angle $(\alpha)$, and the relative ellipse orientation $(\varphi)$. The relative ellipse orientation is the average angle of the major axis of the ellipse of one mooring with re- 
spect to the other. The upward- and downward-looking instruments are highly correlated over low frequencies and the diurnal and semidiurnal tidal bands. These correlations are also significantly above the $90 \%$ SL. Both the phase lag and veering angle are nearly zero at these frequencies. This shows that the velocity vectors from the two moorings are in alignment and are basically indistinguishable. The relative ellipse orientation is also near zero for these frequencies, which means that the major axes of the two moorings are also in alignment. Except for minor variations near the surface when using downward-looking instruments, these results confirm the efficacy of using either mooring configuration.

\section{Discussion and summary}

We compared current observations from five moorings deployed on the WFS with either bottom-mounted upward-looking or surface buoy bridle-mounted downward-looking ADCPs. The moorings were deployed along two orthogonal transects on the 20-, 25-, and $30-\mathrm{m}$ isobaths. Analyses methods consisted of time series comparisons, vector correlations, scalar spectral analysis, and rotary spectral analysis. All methods showed good agreement between the data collected by either type of mooring. Most of the observed differences reflect real regional differences as contrasted with mooring biases. An exception is for measurements in the upper 5-7 $\mathrm{m}$ of the water column when sampled by downward-looking instruments. Given that upwardlooking ADCPs make measurements to within 3-4 m of the surface, due to sidelobe reflections, this nearsurface difference only affected observations covering $6 \%-10 \%$ of the water column. In this region the discernable difference between upward versus downward moorings was an approximate $8.5 \%$ reduction in rms, which translates to a $9 \%$ reduction in the observed velocity. Therefore, for observed velocities of $5 \mathrm{~cm} \mathrm{~s}^{-1}$ amplitude the reduction in the near-surface observations made by a bridle-mounted downward-looking ADCP is $0.5 \mathrm{~cm} \mathrm{~s}^{-1}$, which is comparable to the accuracy of the instrument. For velocities exceeding 20 $\mathrm{cm} \mathrm{s}^{-1}$, such as during extratropical frontal systems (Fig. 4), the near-surface reduction is $1.8 \mathrm{~cm} \mathrm{~s}^{-1}$.

There are many potential explanations for velocity contamination in the downward-looking instruments. These include variations associated with in-line instruments, bin size, biological fouling, and bubbles. A combination of numerous in-line instruments, such as wiremounted temperature and salinity sensors, and small bin size $(0.5 \mathrm{~m})$, may result in a larger variability with depth in the rms profiles; however, these are not responsible for the near-surface velocity reduction. With regard to fouling, near-surface observations may be contaminated by fish in the ADCP beams. This problem is more prevalent for surface moorings because a few weeks after deployment algal growth on the buoy bridle attract fish, which could bias the data (Freitag et al. 1992). Rms profiles for $\mathrm{C} 10$ and C06 (not shown) during the first few weeks of a new deployment, when the mooring components were unaffected by fouling, also showed the decrease in rms near the surface. Therefore, the persistence of this feature cannot be attributed to fouling or fish bias. The final possibility is the existence of surface bubbles, created during increased surface wave activity. The lack of wave data makes this difficult to document, but it has been known to affect ADCP observations by reducing the acoustic energy (Winant et al. 1994). If bubbles are indeed the culprit, then a bridle mounting as used here may be the least intrusive of the surface mooring designs because the transducer heads are removed from bubbles generated by the interaction between the buoy hull and surface waves, and it minimizes moving parts and hence the tendency to produce more bubbles through cavitation or trapping by additional appendages.

The statistics used for these comparisons revealed some interesting results about velocity on the WFS over relatively small spatial scales. All the observations over scales of $10 \mathrm{~km}$ exhibited strong similarity; subtle differences reflected real regional variability, which was larger across the shelf than along the shelf. Additionally, the variability in the across-shelf velocity was larger ( $\sim 20 \%$ of the variance) than the along-shelf velocity ( $\sim 10 \%$ of the variance). Time domain analyses showed no lag or any significant velocity vector orientation differences, and the vector correlation amplitudes were all greater than 0.8 , suggesting that the velocities exhibited strong covariability between the moorings. The spectral analyses were consistent with the time domain analyses. The coherence for the scalar cross spectra (akin to a correlation computed for a scalar time series) was near unity for synoptic and lower frequencies and in the two tidal bands, with essentially zero phase lag. This also suggests strong covariability between the moorings, except that in this case the correlations (coherence) and lags were computed over a range of frequencies. The auto rotary spectra showed rectilinear motion along the shelf in the low frequencies. Tidal geometries for both diurnal and semidiurnal tides were organized more across the shelf than along the shelf where all observed tidal motions are clockwise, consistent with previous observations and model results (He and Weisberg 2002). Using observations from $\mathrm{C} 01$ and $\mathrm{C} 10$ the rotary cross-spectral results were consistent with both scalar and vector time domain re- 
sults, except that the correlations (coherence) and lags were computed over a range of frequencies.

The objective of this study was to address how bottom-mounted upward-looking ADCP velocities compared to surface buoy bridle-mounted downwardlooking ADCP velocities. The differences in observed velocities were mostly related to regional variability. The only exception concerned velocities in the nearsurface water column observed from downwardlooking instruments; however, these differences were minor. Therefore, in a coastal ocean environment, such as the West Florida Shelf, both mooring configurations resulted in high-quality observations. Decoupling of ADCPs from surface moorings may be useful when the mooring cable carries other instruments that could contaminate ADCP bins at those depths through sidelobe reflections. Apart from that problem and a small (apparently) bubble-induced bias near the surface, we find that bridle-mounted, downward-looking ADCPs mounted on surface buoys provide a suitable means for sampling coastal ocean currents.

Acknowledgments. Support was provided by the Office of Naval Research Grants N00014-05-1-0483 and N00014-02-1-0972; the second of these, for the Southeast Atlantic Coastal Ocean Observing System (SEACOOS), is administered by UNC under task order 3-12110-10, and from the National Oceanic and Atmospheric Administration Grant NA04NOS4730174. Discussions with Y. Liu were very helpful. Field work and computing support were provided by Ocean Circulation Group members: Messrs. R. Cole, J. Donovan, C.
Merz, and P. Smith. Mooring work was conducted with the help of the crews of the R/V Suncoaster and R/V Bellows.

\section{REFERENCES}

Freitag, H. P., M. J. McPhaden, and P. E. Pullen, 1992: Fishinduced bias in acoustic Doppler current profiler data. Proc. Oceans '92, Vol. 2, Newport, RI, Ocean Engineering Society of IEEE, 712-717.

He, R., and R. H. Weisberg, 2002: Tides on the west Florida shelf. J. Phys. Oceanogr., 32, 3455-3473.

Irish, J. D., K. E. Morey, and N. R. Pettigrew, 1992: Solarpowered, temperature/conductivity/Doppler profiler moorings for coastal waters with ARGOS positioning and GOES telemetry. Proc. of Oceans '92, Vol. 2, Newport, RI, Ocean Engineering Society of IEEE, 730-735.

Kundu, P. K., 1976: Ekman veering observed near the ocean bottom. J. Phys. Oceanogr., 6, 238-242.

Sciremammano, F., Jr., 1979: A suggestion for the presentation of correlations and their significance levels. J. Phys. Oceanogr., 9, 1273-1276.

Seim, H. E., and C. R. Edwards, 2007: Comparison of buoymounted and bottom-moored ADCP performance at Gray's Reef. J. Atmos. Oceanic Technol., 24, 270-284.

Virmani, J. I., and R. H. Weisberg, 2003: Features of the observed annual ocean-atmosphere flux variability on the west Florida shelf. J. Climate, 16, 734-745.

Weisberg, R. H., B. D. Black, J. C. Donovan, and R. D. Cole, 1996: The west-central Florida shelf hydrography and circulation study: A report on data collected using a surface moored acoustic Doppler current profiler, October 1993 January 1995. Tech. Rep., Department of Marine Science, University of South Florida, 129 pp.

Winant, C., T. Mettlach, and S. Larson, 1994: Comparison of buoy-mounted $75-\mathrm{kHz}$ acoustic Doppler current profilers with vector-measuring current meters. J. Atmos. Oceanic Technol., 11, 1317-1333. 